\title{
Impact of collaboration and funding on the propensity to patent of Canadian biotechnology firms 1999-2005
}

\author{
Catherine Beaudry \\ Department of Mathematics and Industrial Engineering, \\ Polytechnique Montréal, \\ P.O. Box 6079, Station Centre-ville, Montreal, \\ Quebec, H3C 3A7, Canada \\ and \\ Center for Interuniversity Research and Analysis of \\ Organizations (CIRANO), \\ 2020, University Street, 25th Floor Montreal, \\ Quebec, H2A 2A5, Canada \\ E-mail: catherine.beaudry@polymtl.ca
}

\begin{abstract}
Using the four biotechnology uses and development surveys of Statistics Canada, we analyse the importance of collaboration, funding and support, as well as contracting, R\&D and IP strategies on the propensity to patent of Canadian biotechnology firms. Our model accounts for the potential endogeneity due to the simultaneity of some of these strategies. Controlling for various firm characteristics, the stage of development of the firm and the sources of its revenues, we find that collaboration with other firms does matter for patenting, as well as $\mathrm{R} \& \mathrm{D}$, even when controlling for potential endogeneity. IP strategies and contracting out activities also increase the propensity of a firm to patent, and so does angel and venture capital funding.
\end{abstract}

Keywords: innovation; patents; collaboration; funding; R\&D; biotechnology.

Reference to this paper should be made as follows: Beaudry, C. (2014) 'Impact of collaboration and funding on the propensity to patent of Canadian biotechnology firms 1999-2005', Int. J. Biotechnology, Vol. 13, Nos. 1/2/3, pp.22-52.

Biographical notes: Catherine Beaudry holds a $\mathrm{PhD}$ in Economics from the University of Oxford. From her first degree in electrical engineering specialised in satellite technology, she has kept a strong interest on technology, science and innovation. She is an Associate Professor at the Mathematics and Industrial Engineering Department of Polytechnique Montreal, an Adjunct Professor at Université du Québec à Montréal (UQAM), a member of the Centre for Interuniversity Research on Science and Technology (CIRST), and a researcher at the Centre for Interuniversity Research and Analysis of Organizations (CIRANO).

\section{Introduction}

Biotechnology firms require two very important resources to be innovative and eventually to survive: external collaborators/partners (Deeds and Hill, 1996; Oliver, 
2004; Powell et al., 1996) and specific funding according to their stage of development (Hall and Bagchi-Sen, 2002) and that of their products. Not disputing the fact that both are essential for a firm to innovate successfully, an interesting question is which of the two, collaboration or funding, has more impact on innovation or at least on the propensity to patent of a firm.

Firms may develop new innovations in-house, in collaboration with other organisations or simply by contracting out this task. In the first case, internal R\&D is the main driver of new innovations that will eventually be patented. In the second case, both internal and external R\&D are required. Several studies have indicated the importance of collaboration as a complement to the internal innovation capabilities of the firm (Deeds and Rothaermel, 2003; Hagedoorn, 2002). In general, the literature finds a positive influence of collaboration on the innovative performance of firms (Baum et al., 2000; Deeds and Hill, 1996; Faems et al., 2005; Rogers, 2004; Shan et al., 1994; Stuart, 2000). Finally, in the third case, external R\&D yields innovations required that the firm has contracted out.

While some collaboration agreements are accompanied with funding agreements, a great number of other sources of funding are available to biotechnology firms. A number of scholars mention the necessity for venture capital (VC) in the early and highly innovative stages of the firm (Kortum and Lerner, 2000; Engel and Keilbach, 2007). Baum and Silverman (2004) for instance show that government funding has a positive effect on the propensity to patent, but that $\mathrm{VC}$ has no effect. Other studies are in agreement regarding the incapacity of traditional debt financing to provide the right funding for highly risky R\&D phases of projects (Czarnitzki and Kraft, 2009; Hall, 2002; Gompers and Lerner, 2001).

The goal of this paper is to verify that collaboration, funding and government intervention has an influence on innovative performance in the case of small and medium biotechnology firms. Despite their obvious flaws (Griliches, 1990), patents are generally accepted as a measure of innovative performance of firms (Hagedoorn and Cloodt, 2003). We will therefore use patents to measure the propensity to innovate. We have the chance of working with a very complete database on Canadian biotechnology firms, particularly rich for small and medium enterprises (SME), covering eight years of data from 1998 to 2005, collected by Statistics Canada. The data allows the characterisation of a great number of firm attributes over the years, which act as control variables in the models.

Using probit regressions with and without instrumental variables to control for potential endogeneity in the model, our results show that collaboration with other firms does have a positive impact on measured by the number of patent applications of a firm. Distinguishing contracting out R\&D activities from collaboration, the analysis shows a positive effect of contracting out, but a negative effect of contracting in R\&D activities on the propensity to patent. Our results also reveal that only angel and VC to some extent have a positive impact on patenting, while debt financing and government support have no effect. The strong and positive significance of angel capital suggest its greater importance over collaboration. The rest of the article proceeds as follows. Section 2 presents a brief review of the literature, the theoretical framework and related hypotheses. Section 3 describes our research methodology, including data and regression models. Section 4 then presents the regression results. Finally, Section 5 presents a discussion of these findings and draws conclusions from the research. 


\section{Theoretical framework and hypothesis development}

\subsection{Collaboration}

The frequency with which US firms have entered into collaborative agreements has increased dramatically since the 1970s (Hagedoorn and Shakenraad, 1990a, 1990b; Hagedoorn, 2002; Narula and Duysters, 2004; Perkmann and Walsh, 2007). The innovation process is now so intertwined amongst a number of organisations that the locus of innovation (Pisano et al., 1988) has shifted from the single firm towards networks or inter-organisational relationships. Gulati and Singh (1998) note the increasing variety of reasons, types of partners necessary to bring a product to market. Firms collaborate with other organisations for a number of reasons, one of which is to overcome innovation barriers such as short-termism of capital markets, heavy regulatory process (Greis et al., 1995) and lack of resources to conduct large R\&D projects, another is simply to survive (Lane and Lubatkin, 1998; Oliver, 2004; Powell et al., 1996). Over the years, reasons to collaborate have been introduced according to a number of theories. The resource-based view (see for example, Das and Teng, 2000; Hitt et al., 2000; Lavie, 2006) argues that firms collaborate to exploit complementary assets and economies of scale, to build capabilities, to share the risks and costs, etc. According to the transaction cost view (see for instance, Dyer, 1997; King, 2007), which is complementary to the resource-based view, collaboration reduces opportunistic behaviour from partners and internalises knowledge spillovers.

In addition to being increasingly common, collaboration has been positively linked to innovation and to patent propensity by a number of authors. The rationale is simple, before entering into any type of partnership, firms feel the need to protect their own intellectual property (IP) before the partner gains access to that precious knowledge (Katila and Mang, 2003). Patenting may also be the result of the collaborative agreement. For instance, Brouwer and Kleinknecht (1999) find that R\&D collaboration agreements have a positive effect on the probability of applying for a patent. In their study of Finland and Germany, Czarnitzki et al. (2007) conclude that collaboration leads to a better patenting performance of the economy in general.

There is also an extensive literature on strategic alliances that links specific aspects of these alliances to the ensuing innovation performance of firms. For instance, Ahuja (2000) find that firms with extensive alliance activities also patent more and are generally more innovative. The more experience biotechnology firms have in participating in alliances, the greater the performance of these alliances in terms of new drug development, but with diminishing marginal returns (Hoang and Rothaermel, 2005). Focusing on the form that these alliances take, Sampson (2007) argues that alliances have a positive impact on the propensity to patent when the technological diversity of the partner is moderate.

In general, depending on the goal of the collaborative agreement, firms choose different partners (Bercovitz and Feldman, 2007), public institutions and other firms, for instance. For the development of basic science, for example, firms will prefer collaborating with universities (Niosi, 2000). In contrast, to access capital or external paths to the market, firms will favour other biotechnology firms or large pharmaceutical companies for the commercialisation of their products. While the former, collaborating with public institutions, can loosely be associated with exploration, the latter, 
collaborating with private organisations, is generally linked with exploitation. Without formally exploring the question, the paper is somewhat related to the exploration-exploitation dichotomy (March, 1991) and the cycle of discovery of Nooteboom (2000). Exploration aims at "the pursuit of knowledge, of things that might come to be known", and exploitation concentrates on "the use and development of things already known" [Levinthal and March, (1993), p.105]. We might therefore expect that firms that collaborate with other firms plan to use the knowledge developed, which often requires the protection of the intellectual property generated to move forward in the development process.

H1 Firms that collaborate with private organisations have a greater propensity to patent.

\subsection{Private funding and public support}

Depending on the life cycle of the firm, various sources of funding are accessible to the firm. In the case of relatively young and small firms, angels and VC firms are often the first port of call. Controlling for R\&D expenditures, Kortum and Lerner (2000, p.675) find that $\mathrm{VC}$ in the USA has an important impact on the increase in patenting. They suggest that "a dollar of VC appears to be about three times more potent in stimulating patenting than a dollar of traditional corporate R\&D”. More recently, Ueda and Hirukawa (2008) confirm these results, i.e., that VC investment increases patent propensity. Engel and Keilbach (2007) find similar results for Germany. In this last study however, an important nuance is that the patents to which Engel and Keilbach (2007) refer are those applied for by the firm prior to the involvement of venture capitalists, hence confirming the 'innovation first' thesis. After the investment, the number of patent applications does not differ significantly from firms that were not funded by VC firms (Hellmann and Puri, 2000). Hirukawa and Ueda (2008) examined the causality aspect of the relationship between VC and innovation to show that there is little evidence for the 'VC first' hypothesis.

In this paper, we want to examine whether this is also the case for Canadian biotechnology firms. In a rare study at the firm level, Baum and Silverman (2004) examined the causality between $\mathrm{VC}$ and patenting and found that patent applications and patents granted positively affect the likelihood of raising VC ('innovation first'). In contrast, Bertoni et al. (2010) find no evidence that firms that received VC had different patenting propensity prior to receiving VC. Lerner et al. (2008) argue that the patents applied for after the involvement of VC are more cited, but they find no consistent results for the quantity of patents applied for. In a more recent study, however, Popov and Roosenboom (2012) show that VC positively influences innovation measured by the number of patents generated ('VC first'), but that the positive effect of the VC to R\&D ratio on the quantity of patent produced is limited to countries and industries where the ratio is high.

The literature presents mixed evidence regarding which of $\mathrm{VC}$ or innovation comes first. Because the evidence is not conclusive on the matter and that the interest of this paper is on the factors that are associated with innovation performance, we suggest the following hypothesis:

H2 Firms that benefit from angel funding and VC are also more likely to patent. 
Capital markets, VC and initial public offering (IPO) or the issuance of stock, are generally focused on short-term return on investment, which seems far removed from the realities of a domain where the regulatory process is long and cumbersome. Consequently, firms will be obliged to combine a number of sources of funding to go through the entire innovation process, from R\&D to commercialisation (Hall and Bagchi-Sen, 2002).

It is often assumed that debt financing is detrimental to innovation. This Schumpeterian view is based on the fact that " $R \& D$ cannot be used as collateral in credit negotiations with banks" [Czarnitzki and Kraft, (2009), p.376]. R\&D is an expense and its outcome is highly uncertain. As a consequence, banks are very reluctant to fund such endeavours (Hall, 2002). Because R\&D is necessary to successful innovation, less funding for these purposes is likely to negatively affect the propensity of a firm to innovate. For these reasons, Gomper and Lerner (2001) state that banks are unable to adequately finance innovative firms, particularly high-tech firms. Audretsch and Lehmann (2004) then demonstrate that small innovative firms are more likely to be financed by VC than by banks. Hence, as a contrast to hypothesis $\mathrm{H} 3$, we suggest the following hypothesis:

H3 Firms that receive funding from traditional banks tend to patent less.

If the cost of external funding is too high, as Hall (2002) argues, some innovation will not be brought forward. Firms will simply abandon some projects and not devote the socially optimum amount towards R\&D. To remedy this R\&D sub-optimality and to provide an incentive to firms, Government intervention is therefore needed to help fill the gap between the private and social returns to innovation expenditures. Among the Government tools are direct funding, through grants and loans, and tax credits, mainly R\&D tax credits. A number of studies have examined the impact of these tools [see for example the surveys by David et al. (2000) and Hall and van Reenen (2000)]. Almus and Czarnitzki (2003) examine the causal effects of R\&D subsidies on patenting to illustrate their importance in fostering innovation. Cantner and Kösters (2009) find similar results for start-up firms. They suggest that start-up firms that receive R\&D subsidies show a higher patent count than non-subsidised firms.

Relatively few studies have concentrated their analysis on Canadian firms. Bérubé and Mohnen (2009) examine whether firms that receive R\&D subsidies are more innovative, in particular, firms that benefit from both $R \& D$ grants and $R \& D$ tax credits introduce more new products than firms that only benefit from the latter. In the same vein, Czarnitzki et al. (2011) show that R\&D tax credits lead to additional product innovations and increased shares of new or improved products.

In a study of Belgian firms, Cincera (2005) find that while the impact of private (from firms) funding has a positive impact on the number of patent applications, the effect of government funding is not significant. Her argument for justifying these results is that public support is generally intended for long-term fundamental research that will take some time to show an impact on innovative output. As a consequence, we propose the following hypothesis regarding public support of firms:

H4 Firms that receive direct public funding have a higher propensity to patent. 


\section{Methodology}

\subsection{Data}

The data used in this study was collected by Statistics Canada. The responses to the four biotechnology uses and development (BUD) surveys ${ }^{1}$ of 1999, 2001, 2003 and 2005 have been linked to one another to build a quasi-longitudinal database. Because the number of biotechnology firms in Canada is relatively small, all firms involved in biotechnology are surveyed and completion of these questionnaires by the surveyed firms is a legal requirement under the Statistics Act. As a consequence, the obtained response rates are between $60 \%$ and $70 \%$. As such, Statistics Canada considers these surveys to be a census of all biotechnology enterprises. Our sample is therefore representative of the population. Table 1 summarises the number of firms in each survey. In this paper, we will concentrate our analysis on SMEs.

Table 1 Number of firms by size and sector, per survey year

\begin{tabular}{lcccccc}
\hline & 1999 & 2001 & 2003 & 2005 & $1999-2005$ & $2001-2005$ \\
\hline Size & & & & & & \\
$\quad$ Small & 269 & 267 & 352 & 397 & & \\
Medium & 51 & 62 & 77 & 83 & & \\
SMEs & 320 & 329 & 429 & 480 & 1,004 & 810 \\
$\quad$ Large & 37 & 47 & 61 & 52 & & \\
Sector & & & & & & \\
$\quad$ Human health & 150 & 197 & 262 & 310 & & \\
Agriculture and food processing & 118 & 113 & 137 & 146 & & \\
Environment & 35 & 33 & 38 & 39 & & \\
$\quad$ Other & 54 & 32 & 52 & 37 & & \\
Total & 358 & 375 & 490 & 532 & 1,129 & 907 \\
\hline
\end{tabular}

Notes: For the four individual surveys are presented the weighted number of firms using the non-response weights. For the two right-hand columns, the number of firms is not weighted and indicates the size of the sample, i.e., the number of observations. Because the four surveys were not originally planed as a longitudinal study, non-response weights for an individual firm across time cannot be constructed sensibly a posteriori.

The two right-hand columns indicate the number of individual firms that are included in the quasi-longitudinal database resulting from the data linkage. In total, the data used in this paper includes 1,004 observations from 1999 to 2005. In this joint sample, a number of firms have been added to the database over the years, either because they did not exist previously, or because they only converted to biotechnology recently, or simply because they did not answer the questionnaire in previous years. In addition, a number of firms also leave the database because they cease their activities, are merged or acquired, or once again, did not answer the questionnaire. The quasi-longitudinal database thus constructed is a very unbalanced panel. For instance, some firms may have answered the four questionnaires, some only one questionnaire, while others may have responded to one questionnaire in 2001 and to another in 2005. Considering our sample, proper panel data analysis is not feasible. 
The phenomenon of interest is whether firms have innovated in the past two years. More than half of the firms have filed patent applications within the last two years of the survey (for example, the 2005 survey comprises the patent applications of both 2004 and 2005). Our dependent variable, PatApp, indicates if firms have applied for a patent in the past two years.

\subsection{Variables}

To measure the extent to which a firm collaborates with other firms, we include the number of collaborative arrangements that a firm has reported for the year of the survey, $n b$ CollPriv $^{2}$. The survey questionnaire provide a clear definition of cooperative and collaborative arrangements: "Cooperative and collaborative arrangements involve the active participation in projects between your company and other companies or organizations in order to develop and/or continue work on new or significantly improved biotechnology processes, products and/or services. Pure contracting-out work is not regarded as collaboration". This distinction allows us to also include in the analysis contracting activities as an alternative means by which firms acquire knowledge. This variable is presented below.

The second group of variables of interest is related to the private funding and public support of biotechnology firms. As an alternative to revenues in their early life, firms are strongly dependent on external funding. The four surveys asked the firms whether they successfully managed to raise capital, how much they raised and what proportion came from each source of funds. With that information, we construct four funding variables: FundGov measures the total amount of direct funding received from government sources, FundVC represents the total amount of VC received, regardless of its geographical origin $^{3}$, FundAng measures the amount of funds received from family and other providential investors (angels), and finally FundDebt represents the amount borrowed by the firm from traditional banking institutions. Because $\mathrm{VC}$ and angel funding are the very first doors on which to knock, these should have a positive effect on patenting.

In addition to the variables of interest, we include a number of control variables. In addition to the size and age of the firm, which have been studied in great length in the past, we add the basic characteristics of the firm, the stage of its product development, its IP-related strategies, the revenues generated from the firm in addition to a number of sector, time-related and environment dummy variables. These are described in the paragraphs below.

Brouwer and Kleinknecht (1999) find that larger firms have a greater propensity to patent. Arundel et al. (1995) suggest that patents are more important for small firms because they are at a disadvantage regarding other protection mechanisms compared to large firms. Other studies however refute this argument by showing that the importance of patents increases with the size of the firm (Arundel, 2001; Kortum and Lerner, 1999; Hussinger, 2006). These studies include large firms in their analysis. In this paper, we concentrate our analysis on SMEs. The question is then whether this finding still stands without the larger firms included in the sample and within a very specific technology field, i.e., biotechnology. Owen-Smith and Powell (2004) include both the size of the firm and its age as control variables in their analysis of the factors that affect successful patent applications in the Boston biotechnology industry. They find an inverted-U relationship for the age of the firm. Once again, their sample also includes the large enterprises, which are generally older than SMEs and small firms. 
As an alternative to the typical number of employees of the firm, we have access to the number of employees dedicated to biotechnology (from research to IP management, from marketing to operations management), nbEmpBio. This variable proved much more significant than the total number of employees of the firm and will thus be used in this paper as a measure of the size of biotechnology activities.

To account for the fact that a more complete managing team helps the firm obtain better sales results which then contribute to financing R\&D (Woiceshyn and Hartel, 1996), or for the fact that the lack of employees in marketing functions is a barrier to innovation (Hall and Bagchi-Sen, 2002), we include a measure of diversity of biotechnology employment, i.e., regarding research, including lab directors and technicians, regulation and clinical trials, production, finances and marketing, as well as general management. A simple Hirshman-Herfindahl index, HHIEmpBio, based on the share of these five employment tasks is constructed. When the index is closer to 1 , the team is less diverse and more equally distributed among categories, while an index closer to 0 indicates that one category of employee dominates.

As independent additional control variables characterising the firm, we include: the age of the firm, Age; A dummy variable, $d P u b$, which takes the value 1 if the firm is a public firm; A second dummy variable, dMerg, which takes the value 1 if has merged or been acquired. A third dummy variable, $d$ SubsInt, which takes the value 1 if the firm is a subsidiary of an international company; and finally, a fourth dummy variable, dSpinoff, which takes the value 1 if the firm is a spinoff, whether it emerged from a public institution or a private enterprise ${ }^{4}$.

For the collaborative arrangements to be beneficial to the firm, its research team must be able to perform its own R\&D activities, to have knowledge to transmit to other organisations but also for its own absorptive capacity (Cohen and Levinthal, 1990). We therefore include $R D E x p$, which measures the amount of R\&D spent by the firm.

A somewhat related variable is whether the firm has put in place specific strategies for the protection of IP. These strategies should have a positive impact on patenting because of the very nature of the domain. In the questionnaires, the firms rated the importance of knowledge development strategies on their firm's performance on a five-point Lickert scale from low (1) to high importance (5). Two items in the survey relate to IP: developed firm policies and practices for knowledge/intellectual property protection; and conducted an IP audit to ensure protection of products and processes at all stages of development. We construct the variable StratIP with the mean score for these questions to generate a measure of the importance of IP protection in the firm ${ }^{5}$.

In addition to collaborative agreement, external linkages of the firm may also consist in contracting out research activities. For some aspects of the research, a firm might not have the necessary knowledge, know-how or capacity in-house and might want to contract out some of these activities. Generally, the IP generated by the firm contracted to do the work would be expected to belong to the firm that gives the contract. Unless other arrangements (such licensing at a reduced fee or share IP) are made for the IP, we would expect contracting out to have a positive effect on innovation. For this purpose, we include CostContOut, which measures the cost of the contracts granted by the firm to other organisations ${ }^{6}$.

One question that springs to mind is whether the business model of some biotechnology firms is not simply that of the one-product firm, i.e., based on one product brought to the market or brought to phase II of the clinical trials followed by the traditional venture capitalist exit strategy (IPO or acquisition by a another firm). These 
particular firms would thus file for patents early in their life and then follow the product through the pipeline, while neglecting further research or patenting. As a consequence, one may be inclined to think that firms that have products further along the development stage may not be as innovative as they were in the past, and thus that patenting would strongly depend on the stage of the product pipeline reached by the firm. To account for this possibility, we have constructed a variable that takes into consideration the proportion of products that are at various stages of development. The resulting ordered variable, ProdStage, takes the value 1 if the highest proportion of the products is at the R\&D stage, the value 2 if the highest proportion of the products is at the preclinical stage, the value 3 if the highest proportion of the products is at the regulation and clinical trials stage, and the value 4 if the highest proportion of the products is in production or on the market $^{7}$.

In addition to public funding, $\mathrm{VC}$ and debt financing, a firm may well have to resort to research contracting (contracting in) to be able to maintain operations (Hall and Bagchi-Sen, 2002). The authors find that contract or collaboration revenue represented $17 \%$ of all the revenue sources of Canadian biotechnology firms in 1998. In order to finance the laboratories while waiting for the patenting process to takes its course or for the research to reach its goal, some firms subcontract, so to speak, their research facilities. This is a common survival strategy in the field, which allows the firm more time to devote to research or further testing. Such activities would then be associated with IP that belongs to other organisations and would thus have a negative effect on innovation of the firm in question. We measure the revenues from contracting in research activities, RevContIn, rather than the number of contracts, which may not reflect accurately the extent of the contracting activities.

Another important source of revenues in this science-based domain is the licensing fees obtained from leasing, licensing or selling IP to other organisations. For firms that have a strong tradition of patenting, this represents a potentially high source of revenues, which would generally be associated with a positive effect on patenting. Once again, the value of licensing, RevIPR, is more appropriate than say the number of such licenses as it represents the 'quality' or usefulness of the innovation. We also include in the analysis the number of patents owned by the firm, nbPat, as a measure of innovation capability. These are the result of patent applications in the past that are the consequence of R\&D performed a few years back. The IP that does not have direct uses for the firm might be used by another organisation while providing extra revenues to finance the firm's activities.

Once we have accounted for the revenues from contracting in and from IP licensing, revenues from sales are what most firms aspire to. The survey provides information from total sales revenues as well as from exports revenues. We have examined various ways of including domestic sales and exports within the analyses, unfortunately, the distinction did not yield significant results. As a consequence, we include in the regressions the total sales revenues, RevSales, and a dummy variable, dExport, taking the value 1 if the firm has exported products within the past two years of the survey.

Finally, our model includes subdomain dummy variables, for human health, agriculture biotech, environment, and other subdomains, to take into account for any heterogeneity that may not be picked up by other variables, as well as regional dummy variables for provinces and survey-year dummy variables to account for variations in the economic environment across provinces and across time that may affect the firms. 


\subsection{Descriptive statistics}

Table 2 presents the descriptive statistics for SMEs for the most complete sample. The variables for which the number of observations $\mathrm{N}$ is equal to 811 are not present in the 1999 survey. More than 50\% of firms submitted patent applications during the two years covered by each survey for an average 4.7 applications per firm, including those that did not patent. On a five-point Likert scale, firms score an average 3.2 for the importance of an IP strategy, which seems relatively low for a domain for which patents are almost perfectly suited.

Table 2 Descriptive statistics

\begin{tabular}{|c|c|c|c|c|c|}
\hline Variable & $N$ & Mean & S.E. & \multicolumn{2}{|c|}{ Without the natural log } \\
\hline dCollPriv & 1,005 & 0.3174 & $(0.0147)$ & & \\
\hline dCollPub & 1,005 & 0.3114 & $(0.0146)$ & & \\
\hline nbCollPriv & 811 & 1.2377 & $(0.1603)$ & & \\
\hline nbCollPub & 811 & 0.8426 & $(0.0740)$ & & \\
\hline nbEmpRes & 1,005 & 10.3967 & $(0.4075)$ & & \\
\hline nbEmpReg & 1,005 & 1.0348 & $(0.0928)$ & & \\
\hline nbEmpMngt & 1,005 & 1.7446 & $(0.1001)$ & & \\
\hline nbEmp & 1,005 & 26.2256 & $(0.9188)$ & & \\
\hline nbEmpBio & 1,005 & 17.0947 & $(0.6793)$ & & \\
\hline HHIEmpBio & 1,001 & 0.7359 & $(0.0232)$ & & \\
\hline Age & 811 & 10.0814 & $(0.4151)$ & & \\
\hline$d P u b$ & 811 & 0.2182 & $(0.0145)$ & & \\
\hline$d M e r g$ & 811 & 0.1282 & $(0.0117)$ & & \\
\hline$d S u b s I n t$ & 811 & 0.1097 & $(0.0110)$ & & \\
\hline dSpinoff & 1,005 & 0.4030 & $(0.0155)$ & & \\
\hline $\ln (R D \operatorname{Exp})$ & 1,005 & 6.2803 & $(0.0662)$ & $2,804,132$ & $(270,286)$ \\
\hline$n b P a t$ & 1,005 & 6.9241 & $(0.7576)$ & & \\
\hline StratKnow & 811 & 3.2022 & $(0.0350)$ & & \\
\hline StratIP & 811 & 3.1973 & $(0.0436)$ & & \\
\hline$n b P r o d R D$ & 1,005 & 21.8470 & $(7.6095)$ & & \\
\hline nbProdPC & 1,005 & 1.7787 & $(0.3214)$ & & \\
\hline$n b P r o d R C$ & 1,005 & 2.6768 & (1.1693) & & \\
\hline nbProdPM & 1,005 & 15.4642 & $(4.9632)$ & & \\
\hline ProdStage & 1,005 & 3.0229 & $(0.0271)$ & & \\
\hline $\ln ($ CostContOut $)$ & 1,005 & 2.9542 & $(0.0979)$ & $1,375,539$ & $(574,418)$ \\
\hline
\end{tabular}

Notes: All monetary values are in constant dollars of 2002 (deflated by the CPI). The means presented here do not take into account that the same firms may have responded to more than one survey. The means of the characteristics of firm-year combinations are calculated here. For instance, a firm that became a public firm in 2003 would count as a non-public firm for 1999 and 2001 and as a public firm in 2003 and 2005. 
Table 2 Descriptive statistics (continued)

\begin{tabular}{lccccc}
\hline Variable & $N$ & Mean & \multicolumn{2}{c}{ S.E. } & \multicolumn{2}{c}{ Without the natural log } \\
\hline $\ln ($ CostIPR $)$ & 811 & 0.6872 & $(0.0638)$ & 234,775 & $(131,417)$ \\
$\ln ($ RevContIn $)$ & 811 & 1.3514 & $(0.0912)$ & 372,834 & $(77,492)$ \\
$\ln ($ RevIPR $)$ & 811 & 0.4715 & $(0.0579)$ & 129,676 & $(49,021)$ \\
$\ln ($ RevSales $)$ & 811 & 4.8427 & $(0.1243)$ & & \\
$\ln ($ Rev $)$ & 1,005 & 5.3289 & $(0.1195)$ & & \\
$d$ Export & 1,005 & 0.2995 & $(0.0145)$ & & \\
$\ln ($ FundGov $)$ & 1,005 & 0.8997 & $(0.0940)$ & $10,873,950$ & $(2,424,651)$ \\
$\ln ($ FundVC $)$ & 1,005 & 1.9692 & $(0.1449)$ & $107,527,100$ & $(14,180,310)$ \\
$\ln ($ FundDebt $)$ & 1,005 & 0.5754 & $(0.0776)$ & $7,434,544$ & $(2,133,823)$ \\
$\ln ($ FundAng $)$ & 1,005 & 1.0801 & $(0.1031)$ & $89,151,290$ & $(79,927,910)$ \\
$d$ FiscInc & 1,005 & 0.7881 & $(0.0129)$ & & \\
$\ln ($ FiscInc $)$ & 811 & 4.2301 & $(0.0952)$ & 597,224 & $(56,436)$ \\
\hline Nes:All & & & &
\end{tabular}

Notes: All monetary values are in constant dollars of 2002 (deflated by the CPI). The means presented here do not take into account that the same firms may have responded to more than one survey. The means of the characteristics of firm-year combinations are calculated here. For instance, a firm that became a public firm in 2003 would count as a non-public firm for 1999 and 2001 and as a public firm in 2003 and 2005 .

The average firm is ten years old, has 26 employees of which 17 are dedicated to biotechnology activities. Not surprisingly, the distribution of the type of tasks performed by these employees is highly skewed towards research as indicated by the high value of HHIEmpBio and of nbEmpRes. More than $40 \%$ of firms are spinoffs, $22 \%$ have reached their first initial public offer (IPO) stage, 13\% have been merged and $11 \%$ are subsidiaries of foreign organisations.

Amongst the variables used to calculate the stage of product development of the firm, i.e., the number of products in R\&D (nbProdRD), preclinical (nbProdPC) and clinical ( $\operatorname{nbProdRC})$ stages as well as on the market (nbProdPM), we find that the first and last have the most weight. On average, firms have 22 products in the lab and 15 products on the market, which yield an average advancement stage of 3 , roughly equivalent to the 'clinical research' stage.

More than $55 \%$ of firms collaborate with other organisations, $32 \%$ with private firms and $31 \%$ with public institutions. On average, firms participate in 1.24 collaborative agreements with private firms and in 0.84 such agreements with public institutions.

$R \& D$ expenditures are by far the largest expense, compared to the costs of contracting out and of acquiring IP. Part of these costs are compensated by R\&D tax credits which compensate for less than a quarter of R\&D expenditures on average. Part of these expenditures is obviously paid for by generous amounts of $\mathrm{VC}$, and apparently from rather well off angels. Note however the large standard error of this last variable.

\subsection{Model specification}

Our first model, examines the propensity of firms to file patent applications. The basic equation on PatApp to be estimated includes the following set of independent variables: 


$$
\text { PatApp }=\left\{\begin{array}{l}
\text { nbEmpBio, HHIEmp }, d P u b, d \text { Merg }, d \text { SubsInt }, \text { SSpinoff }, \\
n b \text { CollX }, \text { prodStage, nbPat, revContIn, revIPR, revSales, } \\
\text { dExport }, \text { FundGov, FundVC, FundAng, FundDebt }, \\
\text { RDExp, CostContOut, StratIP }
\end{array}\right\}
$$

A firm that invests in R\&D is also likely to have a policy for the protection of the IP generated by this $R \& D$, and may also contract out some of this $R \& D$ to other organisations for the tasks for which the firm does not have the capacity. Because of complementarity, these three variables are likely to be endogenous. To overcome this endogeneity problem, we use an instrumental variables estimation technique. We regress these variables on a set of assumed exogenous variables or instruments in a first step. Then, we use the predicted values of these variables as independent variables in the estimation of equation (1). The Stata procedure ivprobit allows for the second stage standard errors to be consistent. Each of the endogenous variables is estimated on a number of instruments.

As specific instruments for $R \& D$ expenditures, we use the number of employees dedicated to research (including lab directors and technicians), nbEmpRes, which will represent an important part of these expenditures, FiscInc. We also include the amount of the fiscal incentives associated with these R\&D expenditures ${ }^{8}$. Similarly to what Veugelers and Cassiman (2005) use in their regressions, we calculate an average value for each of the sub-domains of biotechnology, $R D E x p S D^{9}$. This sub-domain average is expected to account for any unobserved heterogeneity that might arise from the different realities of each sub-domain.

$$
\text { RDExp }=\{\text { nbEmpres, FiscInc, RDExpSD }\}
$$

Instruments for StratPI include the mean score of three other strategies related to knowledge development, StratKnow. The questionnaire asks the firm to rank the importance of the following items: captured and used knowledge obtained from other industry sources such as industry associations, competitors, clients and suppliers; Captured and used knowledge obtained from public research institutions including universities and government laboratories; used and updated databases of scientific information $^{10}$. These questions relate to the capacity of the firm to turn into new knowledge, products or processes, the information obtained from other sources, private organisations, public institutions or basic science. If the firm aims to develop new IP, it is therefore more likely to want to protect it. We also include the number of employees dedicated to regulatory activities as an instrument, $n b E m p R e g$. The more important is IP protection, the greater the need for such employees. This variable hence measures the capacity of the firm to protect its IP. Similarly to the previous endogenous variable, we also consider the sub-domain average of the instrumented variable, StratIPSD.

$$
\text { StratIP }=\{\text { StratKnow, nbEmpreg, StratIPSD }\}
$$

Finally, the third endogenous variable, CostContOut, is instrumented by the number of collaborative agreements the firm has with public institutions, $n b C o l l P u b$, the costs of the IP rights purchased or licensed from other organisations, CostIPR, and the number of employees dedicated to management, nbEmpMngt. Firms that contract out research are more likely to benefit from collaboration with universities and government laboratories. This can lead to, or emanate from, contracting out research activities to these institutions. 
In contracting out research activities, the resulting IP may not necessarily belong entirely to the firm, or may also require the purchase of IP rights developed by the contractee, in which case, the costs of acquiring IP rights are likely to be related to the costs of contracting out. The coordination of external research activities makes extra managerial demands on the firm, hence the inclusion of the number of biotechnology employees dedicated to management. Negotiations of contracts as well as their subsequent monitoring are demanding tasks that if neglected may result in the failure of the partnership.

$$
\text { CostContOut }=\{\text { nbCollPub, CostIPR, nbEmpMngt }\}
$$

\section{Regression results}

Table 3 presents the results from the probit regressions on PatApp for the SME sample excluding the 1999 survey. The regressions are therefore estimated on a sample of 811 observations corresponding to 528 firms covering the 2001, 2003 and 2005 surveys. The results including the 1999 survey are provided in Appendix 3. Regression (1) shows the results for the model excluding the three endogenous variables.

The number of collaborative agreements with private firms, nbCollPriv, has a positive and significant impact on PatApp. As expected, collaboration does matter for innovation in this high technology domain, a result similar to that of Brouwer and Kleinknecht (1999). During the analysis, we have tried to add non-linear effects, i.e., a quadratic term, for this variable as suggested by Deeds and Hill (1996) who showed that the relationship between the number of collaborative agreements and innovation performance suffers from diminishing marginal returns. This however did not improve the significance of the variable. Moreover, in its dummy variable format, collaborative agreements with private firms yield a positive and highly significant coefficient for the regressions including the 1999 cohort (in Appendix 3).

Table 3 Probit regression results for PatApp - SMEs excluding the 1999 survey

\begin{tabular}{lccccccc}
\hline $\begin{array}{l}\text { SMES } \\
\text { without 1999 }\end{array}$ & $(1)$ & $(2)$ & $(3)$ & $(4)$ & $(5)$ & $(6)$ & $(7)$ \\
\hline nbCollPriv & $0.0429 *$ & $0.0417 *$ & $0.0499 * *$ & $0.0402 *$ & $0.0357^{*}$ & $0.0479 * *$ & 0.0392 \\
& $(0.0224)$ & $(0.0226)$ & $(0.0216)$ & $(0.0226)$ & $(0.0204)$ & $(0.0221)$ & $(0.0260)$ \\
$\ln$ (FundGov) & -0.0195 & -0.0269 & -0.0201 & -0.0183 & $-0.0306 *$ & -0.0198 & -0.0181 \\
& $(0.0180)$ & $(0.0176)$ & $(0.0204)$ & $(0.0180)$ & $(0.0167)$ & $(0.0200)$ & $(0.0183)$ \\
$\ln$ (FundVC) & $0.0289 * *$ & 0.0165 & $0.0239 *$ & $0.0263 * *$ & 0.0032 & $0.0255^{*}$ & $0.0258^{*}$ \\
& $(0.0129)$ & $(0.0135)$ & $(0.0132)$ & $(0.0129)$ & $(0.0139)$ & $(0.0132)$ & $(0.0151)$ \\
$\ln$ (FundDebt) & -0.0089 & -0.0098 & -0.0114 & -0.0086 & -0.0110 & -0.0105 & -0.0086 \\
& $(0.0222)$ & $(0.0223)$ & $(0.0234)$ & $(0.0218)$ & $(0.0215)$ & $(0.0234)$ & $(0.0217)$ \\
$\ln$ (FundAng) & $0.0641 * * *$ & $0.0644 * * *$ & $0.0652 * * *$ & $0.0633 * * *$ & $0.0578 * * *$ & $0.0655^{* * *}$ & $0.0637 * * *$ \\
& $(0.0197)$ & $(0.0207)$ & $(0.0212)$ & $(0.0197)$ & $(0.0195)$ & $(0.0208)$ & $(0.0202)$ \\
\hline
\end{tabular}

Notes: $* * *, * * *$ correspond to the $1 \%, 5 \%$ and $10 \%$ levels of significance, respectively. Standard errors in parentheses. $\mathrm{LL}=\log$ pseudolikelihood. 
Table 3 Probit regression results for PatApp - SMEs excluding the 1999 survey (continued)

\begin{tabular}{|c|c|c|c|c|c|c|c|}
\hline $\begin{array}{l}\text { SMEs } \\
\text { without } 1999\end{array}$ & (1) & (2) & (3) & (4) & (5) & (6) & (7) \\
\hline \multirow[t]{2}{*}{ nbEтpBio } & $0.0083 * *$ & 0.0020 & $0.0084 * * *$ & $0.0074 * *$ & -0.0037 & $0.0084 * * *$ & 0.0072 \\
\hline & $(0.0033)$ & $(0.0034)$ & $(0.0032)$ & $(0.0032)$ & $(0.0037)$ & $(0.0032)$ & $(0.0044)$ \\
\hline \multirow[t]{2}{*}{ HHIEmpBio } & -0.0357 & 0.0348 & 0.1355 & 0.0061 & 0.1501 & 0.0781 & 0.0166 \\
\hline & $(0.2131)$ & $(0.2203)$ & $(0.2183)$ & $(0.2126)$ & $(0.2183)$ & $(0.2284)$ & $(0.2605)$ \\
\hline \multirow[t]{2}{*}{ Age } & -0.0001 & -0.0005 & -0.0009 & -0.0011 & 0.0015 & -0.0007 & -0.0013 \\
\hline & $(0.0060)$ & $(0.0065)$ & $(0.0064)$ & $(0.0061)$ & $(0.0058)$ & $(0.0063)$ & $(0.0066)$ \\
\hline \multirow[t]{2}{*}{$d P u b$} & 0.1947 & 0.0479 & 0.1352 & 0.1530 & -0.0975 & 0.1438 & 0.1426 \\
\hline & $(0.1686)$ & $(0.1762)$ & $(0.1742)$ & $(0.1714)$ & $(0.1702)$ & $(0.1738)$ & $(0.2233)$ \\
\hline \multirow[t]{2}{*}{$d$ Merg } & 0.2833 & 0.2140 & 0.2849 & $0.2912 *$ & 0.1198 & 0.2878 & $0.2913^{*}$ \\
\hline & $(0.1750)$ & $(0.1816)$ & $(0.1807)$ & $(0.1702)$ & $(0.1755)$ & $(0.1777)$ & $(0.1689)$ \\
\hline \multirow[t]{2}{*}{$d$ SubsInt } & -0.1817 & $-0.3174 *$ & -0.1873 & -0.1849 & $-0.4258 * *$ & -0.1829 & -0.1831 \\
\hline & $(0.1655)$ & $(0.1672)$ & $(0.1687)$ & $(0.1655)$ & $(0.1669)$ & $(0.1690)$ & $(0.1675)$ \\
\hline \multirow[t]{2}{*}{ dSpinoff } & $0.2948 * * *$ & $0.2580 * *$ & $0.2412 * *$ & $0.2462 * *$ & 0.1763 & $0.2593^{* *}$ & 0.2297 \\
\hline & $(0.1148)$ & $(0.1181)$ & $(0.1214)$ & $(0.1164)$ & $(0.1151)$ & $(0.1233)$ & $(0.2418)$ \\
\hline \multirow[t]{2}{*}{$\ln (n b P a t)$} & $0.3608 * * *$ & $0.3112^{* * *}$ & $0.3291 * * *$ & $0.3456 * * *$ & $0.2270^{* * *}$ & $0.3373 * * *$ & $0.3391 * * *$ \\
\hline & $(0.0647)$ & $(0.0657)$ & $(0.0647)$ & $(0.0655)$ & $(0.0688)$ & $(0.0646)$ & $(0.1123)$ \\
\hline \multirow[t]{2}{*}{ ProdStage } & $-0.1811 * * *$ & -0.1126 & $-0.1465 * *$ & $-0.1584 * *$ & -0.0284 & $-0.1551 * *$ & -0.1529 \\
\hline & $(0.0704)$ & $(0.0724)$ & $(0.0721)$ & $(0.0698)$ & $(0.0750)$ & $(0.0721)$ & $(0.1012)$ \\
\hline \multirow[t]{2}{*}{$\ln ($ RevContIn $)$} & $-0.0484 * *$ & $-0.0555^{* *}$ & -0.0336 & $-0.0439 *$ & $-0.0601 * * *$ & $-0.0385^{*}$ & -0.0422 \\
\hline & $(0.0225)$ & $(0.0230)$ & $(0.0226)$ & $(0.0227)$ & $(0.0227)$ & $(0.0232)$ & $(0.0330)$ \\
\hline \multirow[t]{2}{*}{$\ln (\operatorname{RevIPR})$} & $0.0780^{*}$ & 0.0640 & 0.0698 & $0.0766^{*}$ & 0.0587 & 0.0704 & 0.0758 \\
\hline & $(0.0453)$ & $(0.0455)$ & $(0.0448)$ & $(0.0456)$ & $(0.0435)$ & $(0.0446)$ & $(0.0464)$ \\
\hline \multirow[t]{2}{*}{$\ln ($ RevSales $)$} & $-0.0567 * * *$ & $-0.0594 * * *$ & $-0.0426 * *$ & $-0.0524 * * *$ & $-0.0562 * * *$ & $-0.0479 * *$ & $-0.0512 *$ \\
\hline & $(0.0198)$ & $(0.0203)$ & $(0.0201)$ & $(0.0198)$ & $(0.0192)$ & $(0.0204)$ & $(0.0268)$ \\
\hline \multirow[t]{2}{*}{ dExport } & 0.0168 & 0.1040 & 0.0330 & 0.0408 & 0.1652 & 0.0247 & 0.0459 \\
\hline & $(0.1306)$ & $(0.1313)$ & $(0.1356)$ & $(0.1306)$ & $(0.1275)$ & $(0.1356)$ & $(0.1447)$ \\
\hline \multirow[t]{2}{*}{$\ln (R D E x p)$} & & $0.2306 * * *$ & & & $0.4424 * * *$ & & \\
\hline & & $(0.0340)$ & & & $(0.0613)$ & & \\
\hline \multirow[t]{2}{*}{ StratIP } & & & $0.3248 * * *$ & & & $0.2130^{*}$ & \\
\hline & & & $(0.0470)$ & & & $(0.1216)$ & \\
\hline \multirow[t]{2}{*}{$\ln ($ CostContOut $)$} & & & & $0.0582 * * *$ & & & 0.0755 \\
\hline & & & & $(0.0188)$ & & & $(0.2310)$ \\
\hline \multirow[t]{2}{*}{ Constant } & -0.1618 & $-1.6174 * * *$ & $-1.3405^{* * *}$ & -0.3368 & $-2.9398 * * *$ & $-0.9485^{*}$ & -0.3855 \\
\hline & $(0.3443)$ & $(0.4216)$ & $(0.3869)$ & $(0.3493)$ & $(0.5431)$ & $(0.5347)$ & $(0.7300)$ \\
\hline
\end{tabular}

Notes: $* * * * *, *$ correspond to the $1 \%, 5 \%$ and $10 \%$ levels of significance, respectively. Standard errors in parentheses. $\mathrm{LL}=\log$ pseudolikelihood. 
Table 3 Probit regression results for PatApp - SMEs excluding the 1999 survey (continued)

\begin{tabular}{lccccccc}
\hline $\begin{array}{l}\text { SMES } \\
\text { without 1999 }\end{array}$ & (1) & (2) & (3) & (4) & (5) & (6) & (7) \\
\hline \multicolumn{7}{c}{ Sector, province and survey-year dummies } \\
\hline Nb observations & 811 & 811 & 811 & 811 & 811 & 811 & 811 \\
Nb firms & 528 & 528 & 528 & 528 & 528 & 528 & 528 \\
Wald $\chi^{2}$ & $193.56^{* * *}$ & $217.63^{* * *}$ & $235.6^{* * *}$ & $191.5^{* * *}$ & $298.15^{* * *}$ & $199.15^{* * *}$ & $191.7^{* * *}$ \\
LL & -390.56 & -369.85 & -366.38 & -386.07 & $-1,796.39$ & $-1,513.96$ & $-2,322.10$ \\
Pseudo $\mathrm{R}^{2}$ & 0.3009 & 0.3380 & 0.3442 & 0.3089 & & & \\
\hline
\end{tabular}

Notes: $* * *, * *, *$ correspond to the $1 \%, 5 \%$ and $10 \%$ levels of significance, respectively. Standard errors in parentheses. LL $=\log$ pseudolikelihood.

Funding sources associated with the early beginnings of a firm, i.e., angels and venture capitalists (FundAng, FundVC), both have a positive effect on the propensity of a firm to file patent applications. Angel funding has a much more robust impact than $\mathrm{VC}$ on the propensity to patent. This should not be surprising; during the early days of the firm, when most spinoffs and newly founded firms are seeking financing for their research activities, seed capital is just about the only source available. Other sources of funding have no effect, in this first regression. The same results are obtained when we include the 1999 cohort (see Appendix 3).

The 'biotech' size of the firm, nbEMPBio, has a positive and significant effect on the likelihood of filing a patent application, hence supporting the findings of Arundel (2001), Kortum and Lerner (1999) and Hussinger (2006). The diversity of employment, HHIEmpBio, within the firm does not however have any impact on the propensity to file patent applications. This result is attributable to the fact that research employment clearly dominates and that the standard deviation of this variable is very small. Alternative methods have to be investigated to find an appropriate measure of the fact that a firm has a complete team.

Not surprisingly, spinoffs do have a positive and highly significant effect on the propensity to file patent applications, regardless of their origin. The common scenario in this domain is that university scientists generally patent their findings through the creation of new firms. In addition, if a firm has patented before and has a portfolio of patents it is highly probable that it will patent again. This result seems to suggest that firms are generally not one-patent firms that aim to commercialise one product.

The results however show that firms further along the commercialisation path are less likely to apply for a patent, i.e., ProdStage has a negative and significant effect. A related variable is the revenues generated from sales, RevSales, which also yields a negative and significant effect on PatApp. Firms that already have sales revenues are generally further in the life cycle of the enterprise. This is also found in the regressions including the 1999 cohort, as the total amount of revenues has a negative and significant impact on the propensity to patent (see Appendix 3). We would have expected that a firm that already exports has also reached some maturity. The coefficient of dExport is however not significant. Two effects may be at play here. First, for some firms, exportation is the ultimate goal and once they have reached it, they receive steady revenues from selling their products abroad. For some other firms, exporting products is a means by which they can generate revenues to finance the development of their main product. 
An important survival strategy of biotechnology firms consists in performing contract work for other organisations in order to use and maintain laboratories facilities and staff. A consequence of this strategy is that firms hence patent less, presumably because the IP developed belongs to the contractor organisation. The revenues generated by these contracts, RevContIn, have a negative and significant effect on the propensity to patent. In contrast, IP revenues have a weakly positive effect on the propensity to patent.

In the next three regressions, (2), (3) and (4), we introduce in turn, the three variables that are considered endogenous in regressions (5), (6) and (7). Regression (2) introduces $R D E x p$ as a measure of the input necessary to generate patentable innovations. Confirming prior studies, R\&D positively influences the likelihood that a firm will patent. The 'biotech' size of the firm, nbEmpBio, loses its impact on the propensity to patent, and so does the stage of advancement of the products of the firm, ProdStage, and the amount raised from VC, FundVC. This suggests an interaction between these three variables and R\&D. First, the amount of R\&D expenditures depend on the size of the firm to some extent, especially for high technology SMEs. Second, the most appropriate source of funding when the firm is still largely in its research phase is VC, hence the reduction in value of the coefficient and its significance. Third, firms spending a great deal on R\&D are most probably in the early stages of their product lifecycle, which contributes the explaining the increase in the value of the coefficient (less negative) and the loss of significance of ProdStage.

When correcting for potential endogeneity (5), RDExp remains positive and strongly significant, but its coefficient almost doubles in value. Two of the instruments of RDExp are significant (as seen in Appendix 2), nbEmpres and FiscInc. In other words, firms that employ more research personnel dedicated to biotech spend more on R\&D expenditures and benefit from larger R\&D tax credits, i.e., fiscal incentives. The subdomain average of $\mathrm{R} \& \mathrm{D}$ does contribute to explaining the variations observed for $R D E x p$. In retrospect, this is not surprising as we are after all studying a science-based domain and not comparing a number of industrial sectors across the economy as most studies that use industrial averages do. It is therefore expected that the costs and intensity of $R \& D$ are relatively similar across all subdomains of biotechnology. With the exception of dSpinoff, which loses its significance in the endogeneity-corrected regression, the other coefficients remain relatively similar between regressions (2) and (5).

Regression (3) adds the IP strategies to the regression. The results show that if a firm has a clear strategy towards the protection of its IP, then it is more likely to patent. In addition, this regression does not generally change the results obtained in regression (1), with the exception of the revenues obtained from contracts, which looses its significance.

Controlling for potential endogeneity yields a positive but weakly significant coefficient for StratIP in regression (6). That being said, the Wald test does not reject the null hypothesis that there is no endogeneity. It is nevertheless interesting to comment on the potential instruments for StratIP. The first stage regression (in Appendix 2) presents significant results for the three instruments of this variable. A firm's strategy towards knowledge development has a positive and strongly significant effect on having also a clear IP strategy. In this case, the subdomain average, StratIPSD, contributes to explaining the propensity to having an IP strategy, the coefficient is positive and strongly significant. Surprisingly, however, the coefficient on the number of employees dedicated to biotech regulation, $n b E m p R e g$, has a negative but weakly significant impact on IP strategy. We would have expected the opposite, as any strategy requires employees to implement it. 
The last potentially endogenous variable to be considered is the cost related to contracting out research activities, CostContOut. Firms that contract out R\&D activities also have a higher likelihood of patenting. Once again, there are no notable variations between regressions (1) and (4). If a firm contracts out research activities, it may want to retain ownership of the IP developed outside the firm. In addition, because it is sometimes difficult to clearly identify the boundaries between what is the IP of the firm and what is being contracted out, or because part of the IP of the firm has to be 'leaked' to the contractee in order to ensure that the contract work is successful and that the firm can appropriate the results within its processes, a firm is more likely to want to protect its IP from potential unwanted spillovers towards the contractee. The data available does not however allow the distinction between the provenance of patents, whether they were contracted out or whether they originated from the firm's own R\&D.

Examining now what happens if we control for endogeneity, we find that CostContOut loses its significance in regression (7). Contracting out research activities does not seem to affect the decision to apply for a patent, once we control for endogeneity. But similarly to regression (6), the Wald test for exogeneity is not significant and implies that regression (4) is probably more appropriate. We will nevertheless comment on the first stage regression, as the results are interesting. We find that the number of collaborative agreements with public institutions has a positive impact on the decision to contract out research activities. Two phenomena may be at play here. First, collaborating firms are generally more open to external research activities and are therefore more likely to enter into formal contracting agreements with partners. Second, we suspect that although the questionnaire specifically stipulates that collaborative agreements are not contracts, firms may misinterpret or confuse the two. Very rarely, firms will collaborate with universities without there being a formal contract, whether financial or regarding the ownership and transfer of IP rights. As such, collaboration with university may appear as both contracts and collaborative agreements. We therefore suspect that measurement error is enhancing the significance of this variable. If firms collaborate, they have to acquire IP rights of the partner in order to be able to use the research results. This variable has a positive effect on the decision to contract out, but it is weakly significant. Surprisingly, the increasing number of biotech management employees that would be needed to put in place and monitor such contracting arrangements is not significant. Again, two phenomena may be influencing this result. First, the management of contracts may be part of a firm-based strategy and would thus not be part of the biotech management team. Second, firms may well neglect to recruit for various reasons, lack of funds being the obvious one, the necessary staff to supervise contracts and collaborative activities as well. This may contribute to their demise, but that is another story that we do not address in this paper.

\section{Discussion and conclusions}

This paper studies which firms are more likely to be patenting their innovations. We build an econometric model of the firm characteristics associated with the propensity to file patent applications using the four BUD surveys that Statistics Canada conducted in 1999, 2001, 2003 and 2005. Merging the four surveys into one database allows the construction of a quasi-longitudinal analysis of the data. 
Earlier in the paper we set out to validate four hypotheses related to external linkages and to the funding of innovation. Our results show that firms that collaborate with other firms have a higher propensity to patent, hence validating our first hypothesis (H1). Firms that are generally open to other organisations, regardless of the reason for this collaboration, tend to be more innovative. This is also corroborated by the fact that contracting out research activities also result in a positive impact.

Three hypotheses were formulated regarding private funding and public support of biotechnology firms. By and large, we find support for only one of the hypotheses proposed. Angel funding and $\mathrm{VC}$ do have a positive effect on the propensity of a firm to patent (H2). At this point, it is important to note that we do not imply any strict causality regarding the 'VC first' or 'innovation first' hypotheses as both measures come from the same survey. Because we are able to distinguish between angel or seed capital and VC, we can nevertheless state that, without the former, firms a less likely to be innovative. Regarding the latter, once we account for R\&D expenditures, the coefficient of VC is no longer significant. This would tend to favour the 'innovation first' hypothesis, but only for venture capital and not for angel or seed capital. Hence $\mathrm{H} 2$ is only partially supported. In the biotechnology domain, angel funding potentially comes first followed by patents and then VC.

In contrast, public direct funding (H4), when its effect is significant, has a negative impact, while debt financing is not detrimental $(\mathrm{H} 3)$ to the firm as its effect is never significant. Our third hypothesis is therefore supported, confirming most of the literature on the subject [see Gompers and Lerner (2001) and Audretsch and Lehman (2004) for example]. In contrast, our fourth hypothesis is rejected, hence supporting the results of Cincera (2005) about the non-significance of government funding on patenting. To generate patents, a firm needs to raise funds from angels.

It is also interesting to report some of the results on the control variables. Our results generally suggest that size has a positive influence on the propensity to patent. This is supported by the literature that generally includes large firms in their sample. Our research shows that this result still holds for SMEs and for a particular category of employees, those dedicated to biotechnology. Out of the basic characteristics of the firm, being a spinoff has the most significant effect on the likelihood that a firm files patent applications. A history of patenting also has a positive effect on the propensity to patent. On the one hand, this result disproves the intuition that the prime aim of biotechnology firms, especially spinoffs, is to bring the product for which the firm was created to the market, either via an IPO, the sale of the IPR or commercialisation. On the other hand, once a firm has the majority of its products in production or on the market, or generates more sales revenues, its propensity to patent decreases considerably.

There are important limitations to this study. First, the four surveys were not planned as a longitudinal study, which limits our ability to follow the firms through their life cycle and the life cycle of their products. This is a domain where it can take ten years to bring a particular drug to the market. Second, there are important holes in the database due to the non-response of firms from one survey to the next. It is imperative that in such high technology domains, where the time-to-market are extremely long, think for instance of genomics where it is expected that 15 years will be the norm, systematic longitudinal studies are put in place to be able to investigate the long term impact of public policies, such as R\&D tax credits, direct grants, etc. In addition, our analysis has not managed to completely deal with the potential endogeneity, particularly that caused by R\&D expenditures. Part of the endogeneity could be solved by lagged variables, but in the 
current dataset this reduces the sample of firms considerably. More research is needed to find the appropriate specification that would completely correct the endogeneity problems.

\section{Acknowledgements}

I acknowledge support from the Social Science and Humanities Research Council of Canada (Grants Numbers 820-2006-0064 and 410-2009-1965) and from the Tom Symon fellowship of Statistics Canada. I am grateful to the Science, Innovation and Electronic Information Division of Statistics Canada and particularly to Fred Gault and Paula Thomson for allowing access to the biotechnology use and development survey database, to Chuck McNiven for his wisdom on the state of biotechnology collaboration in Canada, to Javier Ojarzun for constructing the quasilongitudinal database, and I am particularly indebted to Charlene Lonmo who not only supported the technical aspects of the data analysis but shared her findings and questioning relative to the data. Research assistance was provided by Alessandro Ceschia and Joël Levasseur. The research and analysis are based on data from Statistics Canada and the opinions expressed do not represent the views of Statistics Canada. The author is solely responsible for the contents.

\section{References}

Ahuja, G. (2000) 'Collaboration networks, structural holes, and innovation: a longitudinal study', Administrative Science Quarterly, Vol. 45, No. 3, pp.425-455.

Almus, M. and Czarnitzki, D. (2003) 'The effects of public R\&D subsidies on firms' innovation activities', Journal of Business \& Economic Statistics, Vol. 21, No. 2, pp.226-236.

Arundel, A., van de Paal, G. and Soete, L. (1995) Innovation Strategies of Europe's Largest Industrial Firms. Results of the PACE Survey for Information Sources, Public Research, Protection of Innovations and Government Programmes: Final Report, MERIT.

Arundel, A. (2001) 'The relative effectiveness of patents and secrecy for appropriation', Research Policy, Vol. 30, No. 4, pp.611-624.

Audretsch, D. and Lehmann, E. (2004) 'Financing high-tech growth: the role of banks and venture capitalists', Schmalenbach Business Review, Vol. 56, No. 4, pp.340-357.

Baum, J.A.C., Calabrese, T. and Silverman, B.S. (2000) 'Don't go it alone: alliance network composition and startups' performance in Canadian biotechnology', Strategic Management Journal, Vol. 21, No. 3, pp.267-294.

Baum, J.A.C. and Silverman, B.S. (2004) 'Picking winners or building them? Alliance, intellectual, and human capital as selection criteria in venture financing and performance of biotechnology startups', Journal of Business Venturing, Vol. 19, No. 3, pp.411-436.

Bercovitz, J.E.L. and Feldman, M.P. (2007) 'Fishing upstream: firm innovation strategy and university research alliance', Research Policy, Vol. 36, No. 7, pp.930-948.

Bertoni, F., Croce, A. and D'Adda, D. (2010) 'Venture capital investments and patenting activity of high-tech start-ups: a micro-econometric firm-level analysis', Venture Capital, Vol. 12, No. 4, pp.307-326.

Bérubé, C. and Mohnen, P. (2009) 'Are firms that receive R\&D subsidies more innovative?', Canadian Journal of Economics, Vol. 42, No. 1, pp.206-225.

Brouwer, E. and Kleinknecht, A. (1999) 'Innovative output, and a firm's propensity to patent: an exploration of CIS micro data', Research Policy, Vol. 28, No. 6, pp.615-624. 
Cantner, U. and Kösters, S. (2009) R\&D Subsidies to Start-ups: Effective Drivers of Patent Activity and Employment Growth?, Jena Economic Research Papers, No. 2009.

Cincera, M. (2005) The Link between Firms' R\&D by Type of Activity and Source of Funding and the Decision to Patent, DULBEA Working Paper No. 05-10.RS.

Cohen, W. and Levinthal, D. (1990) 'Absorptive capacity: a new perspective on learning and innovation', Administrative Sciences Quarterly, Vol. 35, No. 1, pp.128-152.

Czarnitzki, D., Ebersberger, B. and Fier, A. (2007) 'The relationship between R\&D collaboration, subsidies and R\&D performance: empirical evidence from Finland and Germany', Journal of Applied Econometrics, Vol. 22, No. 7, pp.1347-1366.

Czarnitzki, D., Hanel, P. and Rosa, J.M. (2011) 'Evaluating the impact of R\&D tax credits on innovation: a microeconometric study on Canadian firms', Research Policy, Vol. 40, No. 2, pp.217-229.

Czarnitzki, D. and Kraft, K. (2009) 'Capital control, debt financing and innovative activity', Journal of Economic Behavior \& Organization, Vol. 71, No. 2, pp.372-383.

Das, T.K. and Teng, B-S. (2000) 'A resource-based theory of strategic alliances', Journal of Management, Vol. 26, No. 1, pp.31-61.

David, P.A., Hall, B.H. and Toole, A. (2000) 'Is public R\&D a complement or a substitute for private R\&D? A review of the econometric evidence', Research Policy, Vol. 29, Nos. 4-5, pp.497-520.

Deeds, D.L. and Hill, C.W. (1996) 'Strategic alliances and the rate of new product development: an empirical study of entrepreneurial biotechnology firms', Journal of Business Venturing, Vol. 11, No. 1, pp.41-55.

Deeds, D.L. and Rothaermel, F.T. (2003) 'Honeymoons and liabilities: the relationship between age and performance in research and development alliances', Journal of Product Innovation Management, Vol. 20, No. 6, pp.468-485.

Dyer, J.H. (1997) 'Effective interfirm collaboration: how firms minimize transaction costs and maximise transaction value', Strategic Management Journal, Vol. 18, No. 7, pp.535-556.

Engel, D. and Keilbach, M. (2007) 'Firm-level implications of early stage venture capital investment - an empirical investigation', Journal of Empirical Finance, Vol. 14, No. 2, pp.150-167.

Faems, D., Van Looy, B. and Debackere, K. (2005) 'Interorganizational collaboration and innovation: toward a portfolio approach', Journal of Product Innovation Management, Vol. 22, No. 3, pp.238-250.

Gompers, P. and Lerner, J. (2001) 'The venture capital revolution', The Journal of Economic Perspectives, Vol. 15, No. 2, pp.145-168.

Greis, N.P., Dibner, M.D. and Bean, A.S. (1995) 'External partnering as a response to innovation barriers and global competition in biotechnology', Research Policy, Vol. 24, No. 4, pp.609-630.

Griliches, Z. (1990) 'Patent statistics as economic indicators: a survey', Journal of Economic Literature, Vol. 28, No. 4, pp.1661-1707.

Gulati, R. and Singh, H. (1998) 'The architecture of cooperation: managing coordination costs and appropriation concerns in strategic alliances', Administrative Science Quarterly, Vol. 43, No. 4, pp.781-814.

Hagedoorn, J. (2002) 'Inter-firm R\&D partnerships: an overview of major trends and patterns since 1960', Research Policy, Vol. 31, No. 4, pp.477-492.

Hagedoorn, J. and Cloodt, M. (2003) 'Measuring innovative performance: is there an advantage in using multiple indicators?', Research Policy, Vol. 32, No. 8, pp.1365-1379.

Hagedoorn, J. and Schakenraad, J. (1990a) 'Strategic partnering and technological cooperation', in Dankbaar, B., Groenewegen, J. and Schenk, H. (Eds.): Perspectives in Industrial Organization, pp.171-191, Kluwer Academic Publishers, The Netherlands. 
Hagedoorn, J. and Schakenraad, J. (1990b) ' Inter-firm partnerships and co-operative strategies in core technologies', in Freeman, C. and Soete, L. (Eds.): New Explorations in the Economics of Technical Change, Pinter, London.

Hall, B.H. (2002) 'The financing of research and development', Oxford Review of Economic Policy, Vol. 18, No. 1, pp.35-51.

Hall, B.H. and van Reenen, J. (2000) 'How effective are fiscal incentives for R\&D? A review of the evidence', Research Policy, Vol. 29, Nos. 4-5, pp.449-469.

Hall, L.A. and Bagchi-Sen, S. (2002) 'A study of R\&D, innovation, and business performance in the Canadian biotechnology industry', Technovation, Vol. 22, No. 4, pp.231-244.

Hellmann, T. and Puri, M. (2002) 'Venture capital and the professionalization of start-up firms: empirical evidence', The Journal of Finance, Vol. LVII, No. 1, pp.169-197.

Hirukawa, M. and Ueda, M. (2008) Venture Capital and Innovation: Which is First?, CEPR Discussion Paper 7090.

Hitt, M.A., Dacin, M.T., Levitas, E., Arregle, J-L. and Borza, A. (2000) 'Partner selection in emerging and developed market contexts: resource-based and organizational learning perspectives', Academy of Management Journal, Vol. 43, No. 3, pp.449-467.

Hoang, H. and Rothaermel, F.T. (2005) 'The effect of general and partner-specific alliance experience on joint R\&D project performance', Academy of Management Journal, Vol. 48, No. 2, pp.332-345.

Hussinger, K. (2006) 'Is silence golden? Patents versus secrecy at the firm level', Economics of Innovation and New Technology, Vol. 15, No. 6, pp.735-752.

Katila, R. and Mang, P.Y. (2003) 'Exploiting technological opportunities: the timing of collaborations', Research Policy, Vol. 32, No. 2, pp.317-332.

King, A. (2007) 'Cooperation between corporations and environmental groups: a transaction cost perspective', Academy of Management Review, Vol. 32, No. 3, pp.889-900.

Kortum, S. and Lerner, J. (1999) 'What is behind the recent surge in patenting?', Research Policy, Vol. 28, pp.1-22.

Kortum, S. and Lerner, J. (2000) 'Assessing the contribution of venture capital to innovation', The RAND Journal of Economics, Vol. 31, No. 4, pp.674-692.

Lane, J.P. and Lubatkin, M. (1998) 'Relative absorptive capacity and interorganizational learning', Strategic Management Journal, Vol. 19, pp.461-477.

Lavie, D. (2006) 'The competitive advantage of interconnected firms: an extension of the resource-based view', Academy of Management Review, Vol. 31, No. 3, pp.638-658.

Lerner, J., Sorensen, M. and Stromberg, P. (2008) 'Private equity and long-run investment: the case of innovation, in Globalization of Alternative Investments Working Papers Volume 1: The Global Economic Impact of Private Equity Reports, World Economic Forum, pp.27-42.

Levinthal, D.A. and March, J.G. (1993) 'The myopia of learning', Strategic Management Journal, Vol. 14, No. S2, pp.95-112.

March, J.G. (1991) 'Exploration and exploitation in organizational learning', Organization Science, Vol. 2, No. 1, pp.71-88.

Narula, R. and Duysters, G. (2004) 'Globalisation and trends in international R\&D alliances', Journal of International Management, Vol. 10, No. 2, pp.199-218.

Niosi, J. (2000) 'Strategy and performance factors behind rapid growth in Canadian biotechnology firms', in de la Mothe, J. and Niosi, J. (Eds.): The Economic and Social Dynamics of Biotechnology, Vol. 21, Kluwer Academic, Boston, Dordrecht and London.

Nooteboom, B. (2000) Learning and Innovation in Organizations and Economies, Oxford University Press, Oxford.

Oliver, A.L. (2004) 'On the duality of competition and collaboration: network-based knowledge relations in the biotechnology industry', Scandinavian Journal of Management, Vol. 20, Nos. 1-2, pp.151-171. 
Owen-Smith, J. and Powell, W.W. (2004) 'Knowledge networks as channels and conduits: the effects of spillovers in the Boston Biotechnology Community', Organization Science, Vol. 15, No. 1, pp.5-21.

Perkmann, M. and Walsh, K. (2007) 'University-industry relationships and open innovation: towards a research agenda', International Journal of Management Reviews, Vol. 9, No. 4, pp.259-280.

Pisano, G., Shan, W. and Teece, D. (1988) 'Joint ventures and collaboration in the biotechnology industry', in Mowery, D.C. (Ed.): International Collaborative Ventures in U.S. Manufacturing, pp.183-222, Ballinger, Cambridge.

Popov, A. and Roosenboom, P. (2012) 'Venture capital and patented innovation: evidence from Europe', Economic Policy, Vol. 27, No. 71, pp.447-482.

Powell, W.W., Koput, K.W. and Smith-Doerr, L. (1996) 'Interorganizational collaboration and the locus of innovation: networks of learning in biotechnology', Administrative Science Quarterly, Vol. 41, No. 1, pp.116-145.

Rogers, M. (2004) 'Networks, firm size, and innovation', Small Business Economics, Vol. 22, No. 2, pp.141-153.

Sampson, R.C. (2007) 'R\&D alliances and firm performance: the impact of technological diversity and alliance organization on innovation', Academy of Management Journal, Vol. 50, No. 2, pp.364-386.

Shan, W., Walker, G. and Kogut, B. (1994) 'Interfirm cooperation and startup innovation in the biotechnology industry', Strategic Management Journal, Vol. 15, No. 5, pp.387-394.

Stuart, T.E. (2000) 'Interorganizational alliances and the performance of firms: a study of growth and innovation rates in a high-technology industry', Strategic Management Journal, Vol. 21, No. 8, pp.791-811.

Ueda, M. and Hirukawa, M. (2008) Venture Capital and Industrial 'Innovation', CEPR Discussion Papers No. 7089.

Veugelers, R. and Cassiman, B. (2005) 'R\&D cooperation between firms and universities. Some empirical evidence from Belgian manufacturing', International Journal of Industrial Organization, Vol. 23, Nos. 5-6, pp.355-379.

Woiceshyn, J. and Hartel, D. (1996) 'Strategies and performance of Canadian biotechnology firms: an empirical investigation', Technovation, Vol. 16, No. 5, pp.231-243.

\section{Notes}

1 Each BUD survey is carried out in two steps. A first questionnaire is sent to the Canadian enterprises that are potentially capable of using or developing biotechnology, in order to identify the reference population. For economic reasons, sampling generally reaches about a $70 \%$ response rate. The methodologists of Statistics Canada then apply non-response weights to the sample by strata (firm size, province and NAICS code). Then a second detailed questionnaire is sent to all firms of the reference population. The same procedure for the non-response correction is applied; the resulting weights are thus a combination of the two non-response weights, from the first and second questionnaires.

2 The dummy version of this variable is also included in the analysis as dCollPriv. The number of collaborative arrangements is not available in the 1999 survey, only whether the firm had collaborative arrangements with various types of partners.

3 The more recent surveys distinguish VC from Canadian, European, American and other sources. Because this reporting is not consistent through out the surveys and mainly because the distinction between the sources did not provide robust results, the aggregated values are used in this paper. 
4 Distinctions between the types of spinoffs where examined during the course of this study, but no significant effects were ever noted. A simpler version of the dummy variable is thus presented in this paper.

5 The Cronbach alpha of the two components of StratIP is 0.7660 , which show a good level of reliability.

6 The most recent survey questionnaires ask the firm to distinguish the total value of contracts by type or organization as well as by the objective of the contract in a matrix format. Because of the complexity of the answers demanded and considering the small proportion of firms that have filled the matrix we will not make use of this rich information. In addition, the matrix to be filled is not identical from one survey to the next, rendering a detailed analysis difficult if at all possible. At the aggregate level, there are less risks of mismeasurement, a firm knows how much it has spent on contracts in total.

7 During the course of the analysis, we have also used the number of products at each stage of development (with and without the natural logarithm) instead of the proportion of products at each stage of development. The results were not as robust and will not be presented.

8 Generally, the vast majority of firms in biotechnology are innovative; this is the name of the game. As a consequence, we expect that the possible selection bias resulting from firms demanding $R \& D$ tax credits or grants is relatively small. We will therefore ignore for this paper, the potential selection bias.

9 The sub-domains are: human health, agriculture biotechnology, food processing, environment, natural resources, aquaculture and bioinformatics.

10 The Cronbach alpha of these three variables is 0.6626 , which is acceptable for an exploratory study. 


\section{Appendix 1}

\section{Correlation matrix}

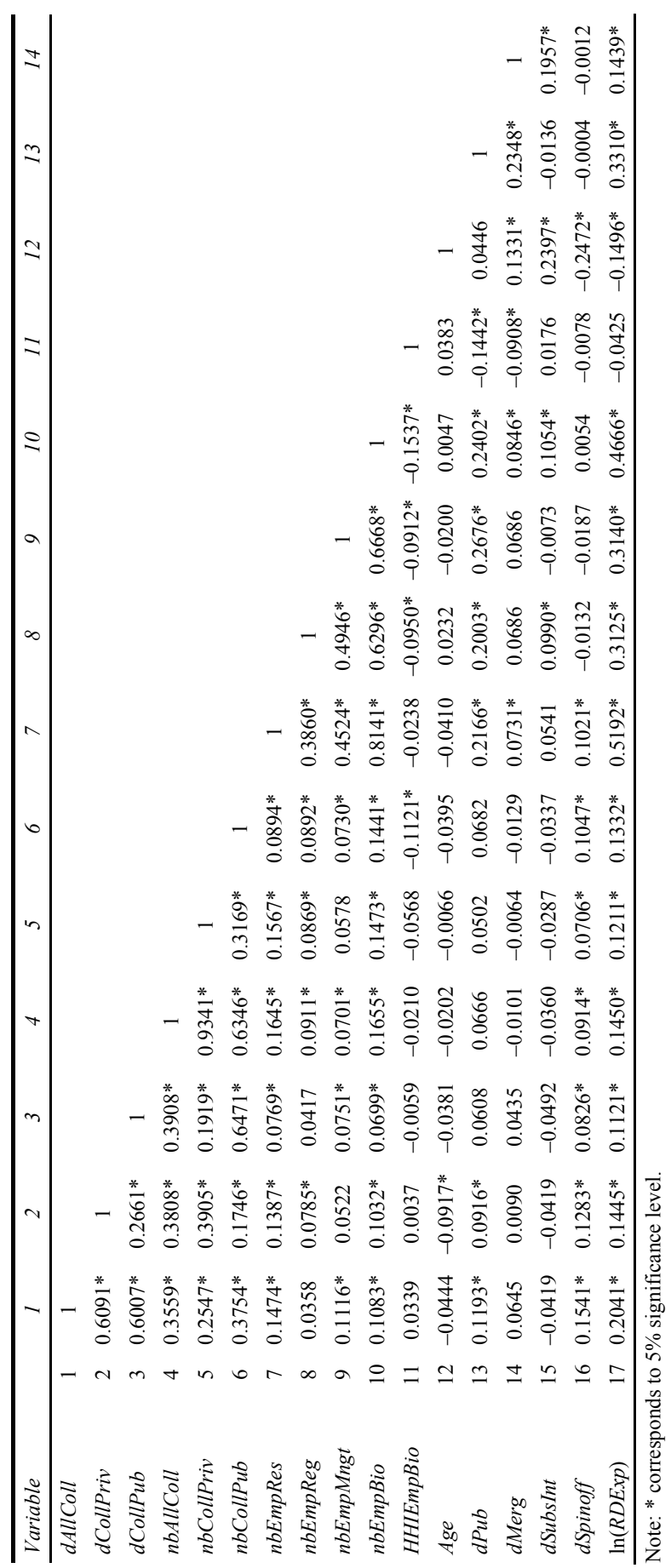




\section{Correlation matrix (continued)}

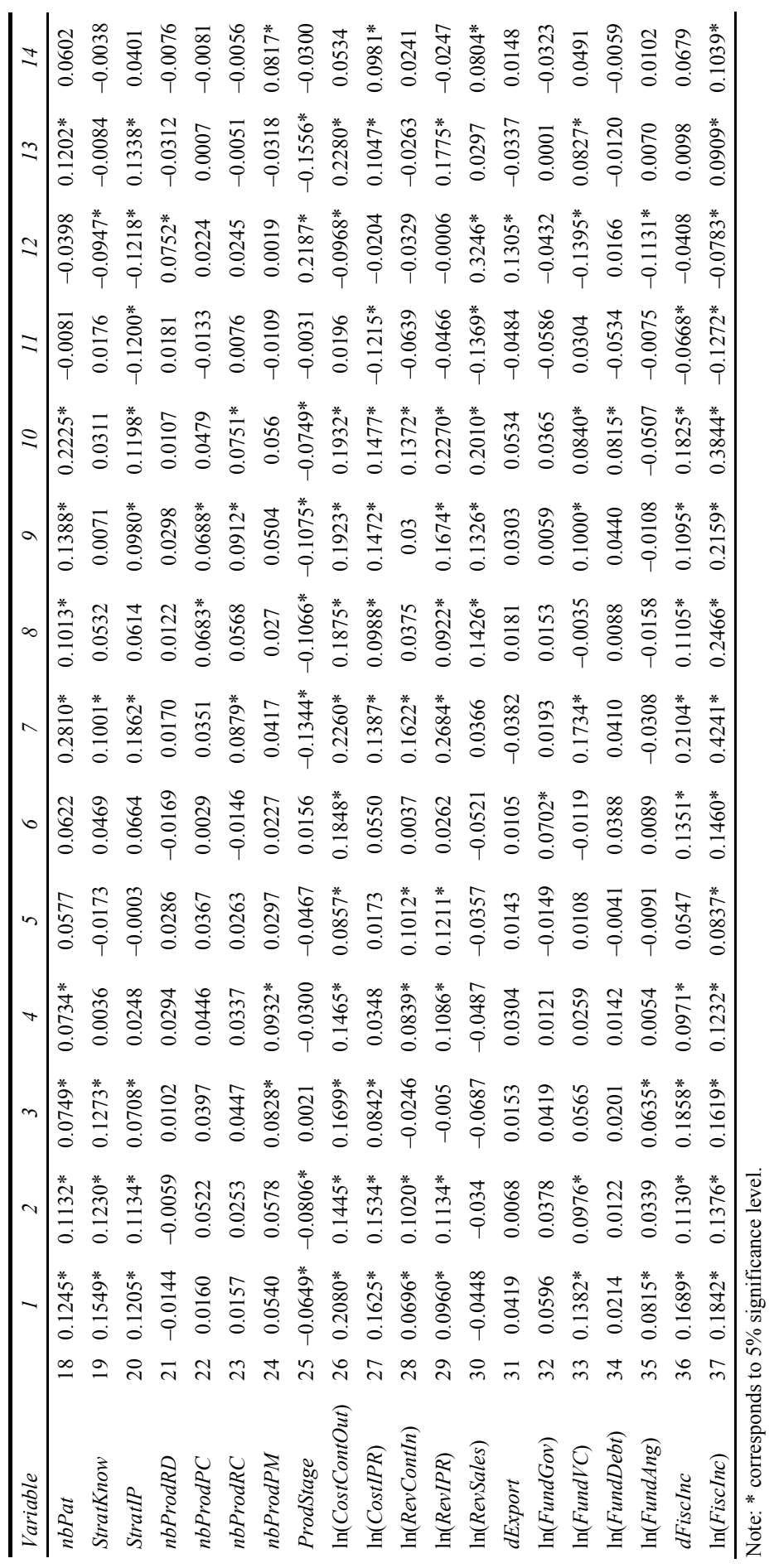


Correlation matrix (continued)

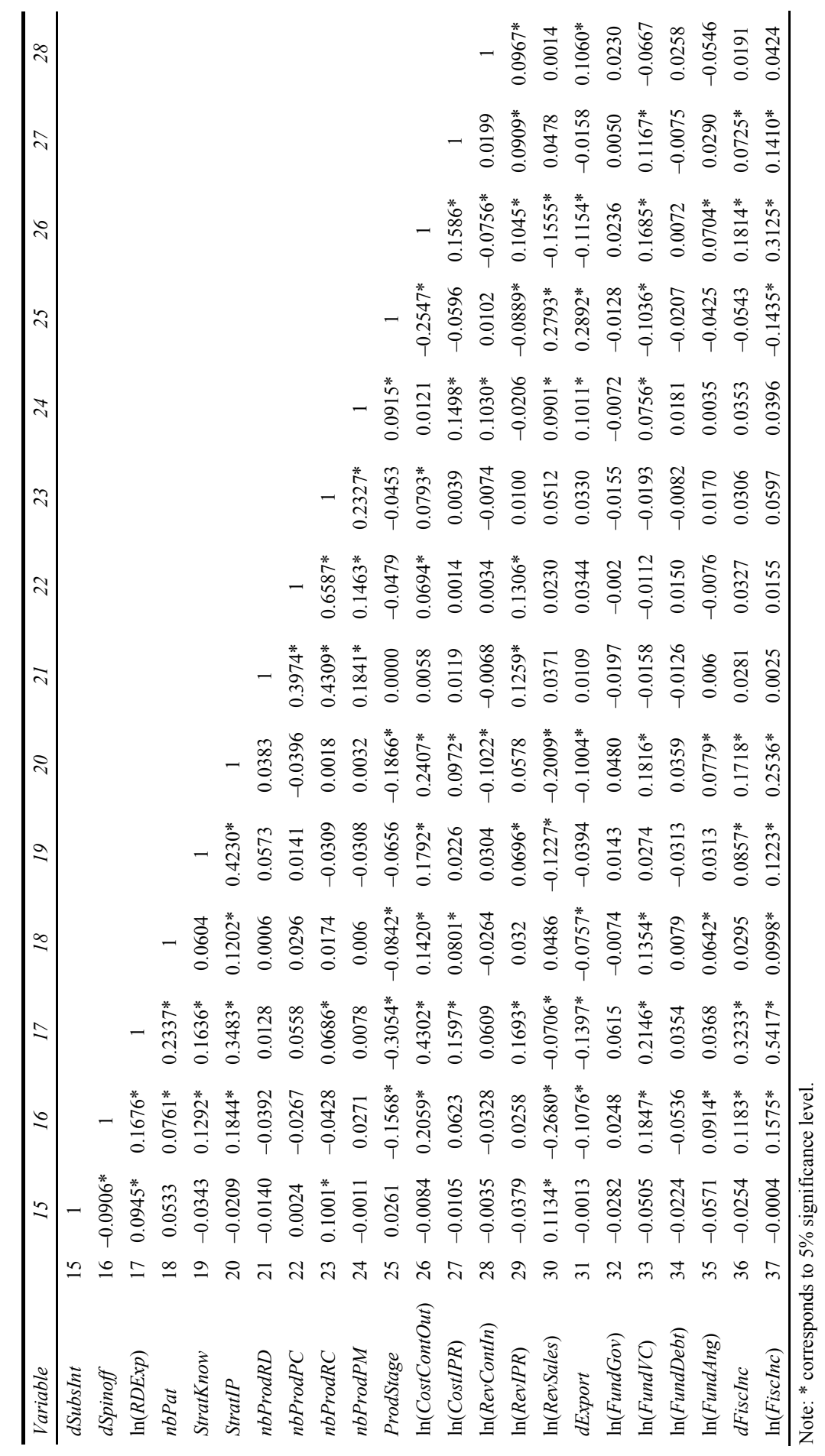


Correlation matrix (continued)

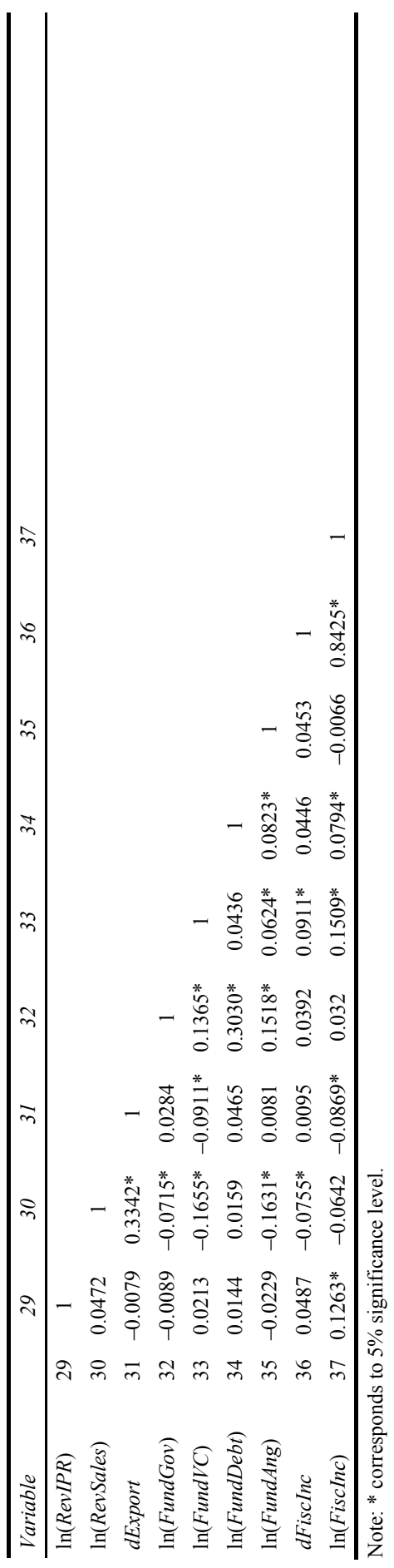




\section{Appendix 2}

Results excluding the 1999 survey

Correction for endogeneity (first stage equation) - SMEs excluding the 1999 survey

\begin{tabular}{|c|c|c|c|}
\hline First stage & (5) $\ln (R D E x p)$ & (6) StratIP & (7) $\ln (\operatorname{Cost} \operatorname{ContOut})$ \\
\hline nbCollPriv & $0.0092(0.0064)$ & $-0.0026(0.0050)$ & $-0.0083(0.0208)$ \\
\hline $\ln ($ FundGov $)$ & $0.0293(0.0161)^{*}$ & $0.0002(0.0141)$ & $-0.0227(0.0378)$ \\
\hline $\ln ($ FundVC) & $0.0359(0.0109)^{* * *}$ & $0.0150(0.0076)^{* *}$ & $0.0321(0.0262)$ \\
\hline $\ln ($ FundDebt $)$ & $-0.0010(0.0217)$ & $0.0126(0.0160)$ & $0.0028(0.0364)$ \\
\hline $\ln ($ FundAng $)$ & $-0.0004(0.0154)$ & $0.0042(0.0136)$ & $-0.0228(0.0333)$ \\
\hline nbEmpBio & $-0.0018(0.0053)$ & $0.0023(0.0021)$ & $0.0090(0.0091)$ \\
\hline HHIEmp & $-0.7536(0.2493)^{* * *}$ & $-0.5577(0.1597)^{* * *}$ & $-0.4407(0.4654)$ \\
\hline Age & $-0.0108(0.0062)^{*}$ & $0.0037(0.0029)$ & $0.0110(0.0088)$ \\
\hline$d P u b$ & $0.7332(0.1485)^{* * *}$ & $0.1360(0.1064)$ & $0.5232(0.2882)^{*}$ \\
\hline dMerg & $0.0648(0.1955)$ & $-0.0044(0.1040)$ & $-0.0691(0.3490)$ \\
\hline dSubsInt & $0.7153(0.1998)^{* * *}$ & $0.0359(0.1246)$ & $0.0074(0.3648)$ \\
\hline dSpinoff & $0.0869(0.1053)$ & $0.1132(0.0821)$ & $0.8229(0.2286)^{* * *}$ \\
\hline $\ln (n b P a t)$ & $0.1973(0.0540)^{* * *}$ & $0.1349(0.0387)^{* * *}$ & $0.3498(0.1041)^{* * *}$ \\
\hline ProdStage & $-0.3375(0.0678)^{* * *}$ & $-0.0879(0.0472)^{*}$ & $-0.3600(0.1254)^{* * *}$ \\
\hline $\ln (\operatorname{RevContIn})$ & $0.0167(0.0204)$ & $-0.0535(0.0153)^{* * *}$ & $-0.0877(0.0411)^{* *}$ \\
\hline $\ln (\operatorname{RevIPR})$ & $-0.0066(0.0260)$ & $0.0003(0.0212)$ & $0.0376(0.0680)$ \\
\hline $\ln ($ RevSales $)$ & $0.0252(0.0195)$ & $-0.0414(0.0125)^{* * *}$ & $-0.0597(0.0354)^{*}$ \\
\hline dExport & $-0.2250(0.1413)$ & $-0.0215(0.0989)$ & $-0.2970(0.2272)$ \\
\hline nbEmpRes & $0.0391(0.0085)^{* * *}$ & & \\
\hline $\ln ($ FiscInc $)$ & $0.2474(0.0272)^{* * *}$ & & \\
\hline $\ln (R D E x p S D)$ & $0.0799(0.1392)$ & & \\
\hline StratKnow & & $0.4712(0.0395)^{* * *}$ & \\
\hline nbEmpReg & & $-0.0298(0.0181)^{*}$ & \\
\hline StratIPSD & & $0.6835(0.1524)^{* * *}$ & \\
\hline nbCollPub & & & $0.1959(0.0567)^{* * *}$ \\
\hline $\ln (\operatorname{CostIPR})$ & & & $0.1359(0.0768)^{*}$ \\
\hline nbEmpMngt & & & $0.0043(0.0850)$ \\
\hline Constant & $5.3067(0.9120)^{* * *}$ & $0.1181(0.4898)$ & $2.7129(0.6962)^{* * *}$ \\
\hline
\end{tabular}

Notes: ***,**,* correspond to the $1 \%, 5 \%$ and $10 \%$ levels of significance, respectively. Standard errors in parentheses. 
Correction for endogeneity (first stage equation) - SMEs excluding the 1999 survey (continued)

\begin{tabular}{lccc}
\hline First stage & (5) $\ln ($ RDExp $)$ & (6) StratIP & (7) $\ln ($ CostContOut $)$ \\
\hline \multicolumn{4}{c}{ Subdomain, province and survey-year dummies } \\
\hline /ath $\rho$ & $-0.4353(0.1254)^{* * *}$ & $0.1353(0.1315)$ & $-0.0472(0.6347)$ \\
$/ \ln (\sigma)$ & $0.3481(0.0423)^{* * *}$ & $-0.0031(0.0238)$ & $0.9683(0.0215)^{* * *}$ \\
$\rho$ & $-0.4097(0.1043)$ & $0.1344(0.1292)$ & $-0.0472(0.6332)$ \\
$\sigma$ & $1.4164(0.0599)^{* * *}$ & $0.9969(0.0237)$ & $2.6334(0.0567)$ \\
Wald test of exogeneity & 12.05 & 1.06 & 0.01 \\
$(/$ ath $\rho=0): \chi^{2}$ & & & \\
Nb observations & 811 & 811 & 811 \\
Nb firms & 528 & 528 & 528 \\
$\mathrm{~F}(29,527)$ & $28.3 * * *$ & $21.22^{* * *}$ & $10.25^{* * *}$ \\
$\mathrm{R}^{2}$ & 0.5539 & 0.3534 & 0.2522 \\
Root MSE & 1.4433 & 1.0158 & 2.6835 \\
\hline
\end{tabular}

Notes: $* * *, * * *$ correspond to the $1 \%, 5 \%$ and $10 \%$ levels of significance, respectively. Standard errors in parentheses.

\section{Appendix 3}

Results including the 1999 survey

Probit regression results for PatApp - SMEs including the 1999 survey

\begin{tabular}{lccccc}
\hline SMEs with 1999 & $\left(1^{\prime}\right)$ & $\left(2^{\prime}\right)$ & $\left(4^{\prime}\right)$ & $\left(5^{\prime}\right)$ & $\left(7^{\prime}\right)$ \\
\hline nbEmpBio & $0.0091^{* * *}$ & 0.0029 & $0.0086^{* * *}$ & -0.0035 & $0.0085^{* * *}$ \\
& $(0.0031)$ & $(0.0030)$ & $(0.0030)$ & $(0.0034)$ & $(0.0033)$ \\
$\ln ($ FundGov $)$ & -0.0206 & -0.0263 & -0.0202 & $-0.0303^{*}$ & -0.0202 \\
& $(0.0170)$ & $(0.0165)$ & $(0.0170)$ & $(0.0158)$ & $(0.0172)$ \\
$\ln ($ FundVC) & $0.0242^{* *}$ & 0.0152 & $0.0220^{*}$ & 0.0050 & 0.0219 \\
& $(0.0119)$ & $(0.0126)$ & $(0.0120)$ & $(0.0129)$ & $(0.0141)$ \\
$\ln ($ FundDebt $)$ & -0.0210 & -0.0218 & -0.0211 & -0.0213 & -0.0212 \\
& $(0.0206)$ & $(0.0210)$ & $(0.0202)$ & $(0.0202)$ & $(0.0201)$ \\
$\ln ($ FundAng $)$ & $0.0465^{* * *}$ & $0.0445^{* * *}$ & $0.0441^{* * *}$ & $0.0382^{* *}$ & $0.0440^{* * *}$ \\
& $(0.0157)$ & $(0.0159)$ & $(0.0157)$ & $(0.0152)$ & $(0.0165)$ \\
HHIEmp & 0.0352 & 0.0202 & 0.0247 & 0.0049 & 0.0239 \\
& $(0.0711)$ & $(0.0662)$ & $(0.0695)$ & $(0.0548)$ & $(0.0800)$ \\
dCollPriv & $0.3110^{* * *}$ & $0.2824^{* * *}$ & $0.2887^{* * *}$ & $0.2122^{* *}$ & $0.2870^{* *}$ \\
& $(0.0972)$ & $(0.0990)$ & $(0.0978)$ & $(0.1029)$ & $(0.1387)$ \\
\hline
\end{tabular}

Notes: $* * *, * *, *$ correspond to the $1 \%, 5 \%$ and $10 \%$ levels of significance, respectively. Standard errors in parentheses. $\mathrm{LL}=\log$ pseudolikelihood. 
Probit regression results for PatApp - SMEs including the 1999 survey (continued)

\begin{tabular}{|c|c|c|c|c|c|}
\hline SMEs with 1999 & $\left(1^{\prime}\right)$ & $\left(2^{\prime}\right)$ & $\left(4^{\prime}\right)$ & $\left(5^{\prime}\right)$ & $\left(7^{\prime}\right)$ \\
\hline \multirow[t]{2}{*}{ dSpinoff } & $0.2369 * *$ & $0.2044^{*}$ & $0.2133^{* *}$ & 0.1433 & 0.2113 \\
\hline & $(0.1038)$ & $(0.1066)$ & $(0.1050)$ & $(0.1060)$ & $(0.1506)$ \\
\hline \multirow[t]{2}{*}{$\ln (n b P a t)$} & $0.4294 * * *$ & $0.3761 * * *$ & $0.4098 * * *$ & $0.2817 * * *$ & $0.4083^{* * *} *$ \\
\hline & $(0.0550)$ & $(0.0567)$ & $(0.0554)$ & $(0.0727)$ & $(0.0998)$ \\
\hline \multirow[t]{2}{*}{ ProdStage } & $-0.1673^{* * *}$ & -0.0946 & $-0.1456 * *$ & 0.0022 & -0.1441 \\
\hline & $(0.0601)$ & $(0.0621)$ & $(0.0605)$ & $(0.0712)$ & $(0.1057)$ \\
\hline \multirow[t]{2}{*}{$\ln (\operatorname{Rev})$} & $-0.0753^{* * *}$ & $-0.0911 * * *$ & $-0.0746^{* * *}$ & $-0.0958 * * *$ & $-0.0746^{* * *}$ \\
\hline & $(0.0182)$ & $(0.0194)$ & $(0.0183)$ & $(0.0192)$ & $(0.0185)$ \\
\hline \multirow[t]{2}{*}{ dExport } & 0.0882 & 0.1778 & 0.1030 & $0.2463 * *$ & 0.1038 \\
\hline & $(0.1160)$ & $(0.1177)$ & $(0.1162)$ & $(0.1142)$ & $(0.1242)$ \\
\hline \multirow[t]{2}{*}{$\ln (R D E x p)$} & & $0.2022 * * *$ & & $0.4105 * * *$ & \\
\hline & & $(0.0287)$ & & $(0.0715)$ & \\
\hline \multirow[t]{2}{*}{$\ln ($ CostContOut $)$} & & & $0.0469 * * *$ & & 0.0502 \\
\hline & & & $(0.0172)$ & & $(0.1877)$ \\
\hline \multirow[t]{2}{*}{ Constant } & -0.2723 & $-1.4701 * * *$ & -0.3952 & $-2.6780 * * *$ & -0.4036 \\
\hline & $(0.2783)$ & $(0.3364)$ & $(0.2850)$ & $(0.5193)$ & $(0.5640)$ \\
\hline \multicolumn{6}{|c|}{ Subdomain, province and survey-year dummies } \\
\hline $\mathrm{Nb}$ observations & 1,001 & 1,001 & 1,001 & 1,001 & 1,001 \\
\hline $\mathrm{Nb}$ firms & 606 & 606 & 606 & 606 & 606 \\
\hline Pseudo $\mathrm{R}^{2}$ & 0.2837 & 0.3171 & 0.2896 & & \\
\hline LL & -492.76 & -469.77 & -488.67 & $-2,322.00$ & $-2,922.37$ \\
\hline$\chi^{2}$ & $218.49^{* * *}$ & $245.59^{* * *}$ & $217.37 * * *$ & $333.16^{* * *}$ & $218.71 * * *$ \\
\hline
\end{tabular}

Notes: $* * *, * * *$ correspond to the $1 \%, 5 \%$ and $10 \%$ levels of significance, respectively. Standard errors in parentheses. $\mathrm{LL}=\log$ pseudolikelihood.

Correction for endogeneity (first stage equation) - SMEs including the 1999 survey

\begin{tabular}{lcc}
\hline First stage & $\left(5^{\prime}\right)$ & $\left(7^{\prime}\right)$ \\
\hline dCollPriv & $0.1027(0.0969)$ & $0.3280(0.2175)$ \\
$\ln ($ FundGov $)$ & $0.0344(0.0148)^{* *}$ & $0.0043(0.0349)$ \\
$\ln ($ FundVC) & $0.0332(0.0113)^{* * *}$ & $0.0369(0.0235)$ \\
$\ln ($ FundDebt $)$ & $-0.0008(0.0219)$ & $0.0099(0.0339)$ \\
$\ln ($ FundAng $)$ & $0.0055(0.0119)$ & $0.0213(0.0294)$ \\
nbEmpBio & $0.0089(0.0041)^{* *}$ & $0.0032(0.0076)$ \\
HHIEmp & $0.0575(0.0894)$ & $0.2185(0.1028)^{* *}$ \\
\hline
\end{tabular}

Notes: $* * *, * * *$ correspond to the $1 \%, 5 \%$ and $10 \%$ levels of significance, respectively. Standard errors in parentheses. 
Correction for endogeneity (first stage equation) - SMEs including the 1999 survey (continued)

\begin{tabular}{|c|c|c|}
\hline First stage & $\left(5^{\prime}\right)$ & $\left(7^{\prime}\right)$ \\
\hline dSpinoff & $0.1132(0.0976)$ & $0.5731(0.2079)^{* * *}$ \\
\hline $\ln (n b P a t)$ & $0.2882(0.0505)^{* * *}$ & $0.4379(0.0892)^{* * *}$ \\
\hline ProdStage & $-0.3855(0.0642)^{* * *}$ & $-0.4761(0.1146)^{* * *}$ \\
\hline $\ln (\operatorname{Rev})$ & $0.0611(0.0199)^{* * *}$ & $-0.0072(0.0347)$ \\
\hline dExport & $-0.3640(0.1330)^{* * *}$ & $-0.2529(0.2079)$ \\
\hline nbEmpRes & $0.0379(0.0068)^{* * *}$ & \\
\hline dFiscInc & $1.0012(0.1536)^{* * *}$ & \\
\hline $\ln (R D \operatorname{Exp} S D)$ & $0.2879(0.1233)^{* *}$ & \\
\hline dCollPub & & $0.7625(0.2204)^{* * *}$ \\
\hline nbEmpMngt & & $0.0607(0.0580)$ \\
\hline Constant & $3.1804(0.8970)^{* * *}$ & $2.3829(0.5202)^{* * *}$ \\
\hline /ath $\rho$ & $-0.4004(0.1557)^{* * *}$ & $-0.0091(0.5253)$ \\
\hline$/ \ln (\sigma)$ & $0.4352(0.0376)^{* * *}$ & $1.0123(0.0208)^{* * *}$ \\
\hline$\rho$ & $-0.3802(0.1332)$ & $-0.0091(0.5252)$ \\
\hline$\sigma$ & $1.5452(0.0581)$ & $2.7520(0.0571)$ \\
\hline Wald test of exogeneity $(/ \operatorname{ath} \rho=0): \chi^{2}$ & $6.61 * * *$ & 0.00 \\
\hline $\mathrm{Nb}$ observations & 1001 & 1001 \\
\hline $\mathrm{Nb}$ firms & 606 & 606 \\
\hline$F(23,605) R^{2}$ & $30.660 .4574 * * *$ & $14.170 .2145^{* * *}$ \\
\hline Root MSE & 1.5641 & 2.7841 \\
\hline
\end{tabular}

Notes: $* * *, * * *$ correspond to the $1 \%, 5 \%$ and $10 \%$ levels of significance, respectively. Standard errors in parentheses. 